\title{
Sleep Apnea and Serum Serotonin Level Pre- and Post- PAP Therapy: A Preliminary Study
}

\author{
Irina M. Madaeva (D) - Olga N. Berdina (D) - Nadezhda A. Kurashova (D) • \\ Natalya V. Semenova (D) · Erdem B. Ukhinov (D) · Aleksey V. Belskikh (D) • \\ Lyubov I. Kolesnikova (D)
}

Received: August 19, 2021 / Accepted: October 5, 2021 / Published online: October 20, 2021

(C) The Author(s) 2021

\begin{abstract}
Introduction: The high prevalence of obstructive sleep apnea (OSA), which impairs quality of life for numerous patients and leads to various OSA complications, has contributed to the continued interest in this disorder. The role of serotonin (5-HT) in many physiological processes, studies on its connection with the circadian system, and relationship to changes in sleep architecture are insufficient to assess the interaction of this neurotransmitter with nocturnal hypoxia. The aim of this study was to determine changes in sleep patterns and serum
\end{abstract}

I. M. Madaeva $(\bowtie) \cdot$ O. N. Berdina · E. B. Ukhinov Laboratory of Somnology and Neurophysiology, Scientific Centre for Family Health and Human Reproduction Problems, 16, Timiryazev str., Irkutsk 664003, Russia

e-mail: nightchild@mail.ru

N. A. Kurashova · N. V. Semenova

Laboratory of Pathophysiology, Scientific Centre for Family Health and Human Reproduction Problems, Irkutsk, Russia

\section{A. V. Belskikh}

Laboratory of Personalized Medicine, Scientific Centre for Family Health and Human Reproduction Problems, Irkutsk, Russia

L. I. Kolesnikova

Scientific Centre of Family Health and Human

Reproduction Problems, Irkutsk, Russia serotonin levels before and after positive airway pressure (PAP) therapy in patients with OSA.

Methods: The study involved 30 OSA patients (27 men and 3 women) who were treated with PAP for 3 months. Polysomnography using the GRASS TELEFACTOR (USA) and blood collection were conducted before and after PAP courses. Determination of serum serotonin was performed by high-performance liquid chromatography (HPLC). PAP therapy was performed using an automatic Prisma 20A (Germany) continuous positive airway pressure (CPAP) device.

Results: The use of PAP for 3 months revealed a significant improvement as measured by sleep data and serotonin levels (before: apnea index [AI] $17.2 \mathrm{eV} / \mathrm{h}, \quad$ after: $2.4 \mathrm{eV} / \mathrm{h} \quad p=0.001$; $\mathrm{SpO}_{2}<90 \%-45.7 \mathrm{~min}$ vs. $6.2 \mathrm{~min} p=0.001$; serotonin $\quad 20.3 \mathrm{ng} / \mathrm{mL} \quad$ vs. $\quad 26.03 \mathrm{ng} / \mathrm{mL}$ $p=0.036]$.

Conclusion: Our results demonstrate an improvement in sleep patterns. There was an increase in serum serotonin levels in OSA patients following PAP therapy, which could be an effect of intermittent hypoxia decline, and could be used as criteria for the effectiveness of PAP and an improvement in sleep quality.

Keywords: Obstructive sleep apnea; Serum serotonin; Sleep pattern; Intermittent hypoxia; PAP therapy 


\section{Key Summary Points}

The high prevalence of obstructive sleep apnea (OSA), the resulting impaired quality of life, and the various OSA complications have contributed to continued interest in learning about the different pathophysiological aspects of this disorder.

The serotonin system regulates autonomic response and arousal during sleep apnea episodes.

Our results demonstrate improvement in sleep patterns and an increase in serum serotonin levels in OSA patients after positive airway pressure (PAP) therapy.

An increase in serum serotonin levels in OSA patients after PAP may be an effect of decreased intermittent hypoxia and may constitute criteria for the effectiveness of PAP and an improvement in sleep quality.

\section{INTRODUCTION}

Obstructive sleep apnea (OSA) is a common sleep disorder characterized by snoring, obstruction of the upper airways, and intermittent nocturnal hypoxia, resulting in significant consequences for health and quality of life. OSA is a major cause of fatal sleepiness-related road vehicle accidents, heart attacks, and strokes [1-6]. Globally, 936 million people aged 30-69 years have OSA, with about 425 million adults having moderate to severe OSA [7]. The high prevalence of OSA, the resulting impaired quality of life, and various OSA complications have contributed to the continued interest in learning about the different pathophysiological aspects of the disorder [8, 9]. It is known that the serotonergic system (namely, serotonin or 5-hydroxytryptamine; 5-HT) has a central role as a neurobiological substrate underlying the regulation of upper airway muscle tone during sleep [10]. 5-HT neurons stimulate respiratory function during hypoxia through activation of the motor neurons controlling the activity of the upper airways [11]. The serotonin system also regulates autonomic response and arousal during sleep apnea episodes [12]. Therefore, the potential use of 5-HT as a pharmacological complement to OSA therapy has been widely discussed [13-15].

Despite active interest in the role of 5-HT in many physiological processes, studies on its connection with the circadian system (including the sleep-wake cycle) and relationship with changes in sleep architecture are insufficient to assess the interaction of this neurotransmitter with nocturnal hypoxia. Positive airway pressure (PAP) therapy is well known as the gold standard for treating patients with moderate to severe OSA [16-18]. It has been reported that PAP therapy is effective in correcting endothelial dysfunction and reducing systemic inflammation [19] and inhibiting enhanced erythropoiesis and changes in some metabolic parameters (e.g., homeostasis model assessment index, glycosylated hemoglobin level) [20].

Therefore, the assessment of sleep patterns and changes in blood serotonin levels with and without (after PAP therapy) nocturnal hypoxia in OSA patients is of great interest. The aim of this study was to determine changes in sleep patterns and serum serotonin levels before and after PAP therapy in patients with OSA.

\section{METHODS}

\section{Study Design and Participants}

The study included 30 patients (27 men and 3 women) who applied to the Somnology Center of the Scientific Center for Family Health and Human Reproduction in Irkutsk with complaints of snoring, apnea episodes during sleep, and increased daytime sleepiness. The mean age was 46.1 (39.8-56.5) years, mean body mass index (BMI) was $26.7(27.0-31) \mathrm{kg} / \mathrm{m}^{2}$, and $78.5 \%$ of patients were male. Comorbidities included arterial hypertension (25\%), ischemic heart disease $(7.6 \%)$, chronic obstructive 
pulmonary disease (7.6\%), chronic gastritis (15\%), and chronic prostatitis (35.7\%).

The inclusion criteria were age from 45 to 60 years, high-risk score of 5 to 8 on STOPBANG questionnaire [21], and clinical diagnosis of moderate obstructive sleep apnea syndrome (OSAS) established by polysomnographic study according to the criteria of the American Academy of Sleep Medicine [22, 23].

Exclusion criteria were previous treatment for OSA with PAP or surgery, worsening and exacerbation of chronic disease, shift work, or refusal to participate in the study. Patients on bi-level positive airway pressure (BiPAP) therapy were excluded from the study due to the need for more stringent respiratory support regimens.

All patients, in accordance with the approved recommendations [22, 23], were selected for PAP therapy titration followed by continuous ventilation during sleep performed using an automatic Prisma 20A continuous positive airway pressure (CPAP) device (Löwenstein Medical, Germany) for 3 months.

Polysomnographic monitoring was carried out in a specially equipped room of the sleep center, as close as possible to home conditions, using the GRASS-TELEFACTOR Twin PSG (Comet) system with an AS40 amplifier with an integrated SPM-1 sleep module (USA), according to the standard method. The protocol consisted of full-night 16-channel polysomnography with two electroencephalogram $(\mathrm{C} 4, \mathrm{C} 3, \mathrm{O} 1, \mathrm{O} 2)$, two electrooculogram, and two electromyogram channels; control of air flow in the nose and mouth through a thermistor; breathing effort through the conductive straps on the chest and abdomen; snoring through a microphone; and determination of blood oxygen saturation using a digital sensor. OSA was classified as mild (apnea/ hypopnea index (AHI): 10.0-15 events/h), moderate (AHI: 15.1-30 events/h), or severe (AHI > 30 events/h) [1].

Participants were treated with PAP as per guidelines [24, 25]. All patients underwent an auto-PAP trial to determine individual PAP requirements. Initial auto-PAP settings were $16 / 6 \mathrm{cmH}_{2} \mathrm{O}$ and were automatically titrated. Adherence to PAP therapy was monitored by electronic download from the unit every
2 weeks once satisfactory PAP adherence was achieved (defined as PAP use for $4 \mathrm{~h} /$ night on $70 \%$ of nights for 12 weeks) $[26,27]$.

\section{Serum Serotonin Collection}

Venous blood was collected between 8:00 and 9:00 am in test tubes after a 12-h overnight fast and polysomnographic examination. The samples were centrifuged for $10 \mathrm{~min}$ at $1.500 \times \mathrm{g}$ at $4{ }^{\circ} \mathrm{C}$. Serum was used to determine the serotonin level. The samples were kept frozen at $-40{ }^{\circ} \mathrm{C}$ for up to 1 month.

\section{High-Performance Liquid Chromatography}

Determination of serotonin was performed by high-performance liquid chromatography (HPLC) with tandem mass spectrometry. For the determination, a Shimadzu (Kyoto, Japan) LC30 Nexera X2 HPLC system with an automatic injector and a Shimadzu LCMS-8060 threequadrupole tandem mass spectrometer was used. The device was controlled using the LabSolutions software package (Shimadzu). Separation of the mixture components was carried out using an AkzoNobel/Kromasil 100-2.5-C18 chromatographic column.

Analyses were determined in selected reaction monitoring mode (SRM) by ions: $177.20>160.15$ for serotonin. The calibration range was $10-30,000 \mathrm{pg} / \mathrm{ml}$.

\section{Statistical Data Analysis}

The data obtained were processed using Statistica 10.1 software (StatSoft, Inc., USA). When analyzing intergroup differences for independent samples, the Mann-Whitney $U$-test was used. Data are presented as median (Me) and 25th and 75th quartiles (Q1-Q3). For comparison in groups before and after treatment, the Wilcoxon $t$-test was used for linked samples. All differences were considered statistically significant at $p<0.05$.

The study was conducted after obtaining the informed consent of the participants, as stipulated by the ethical standards of the World 
Medical Association's Declaration of Helsinki. The study protocol was approved by the Biomedical Ethics Committee of the Federal State Budgetary Institution "Scientific Center for Family Health and Human Reproduction" (20.02.2019, protocol N2).

\section{RESULTS}

The complete elimination of episodes of apnea and restoration of blood oxygen saturation levels significantly changed the structural characteristics and indicators of sleep. Before PAP treatment, we found changes in sleep architecture as a significant decrease in sleep efficiency, a decrease in the representation of slow-wave sleep (SWS) and rapid eye movement sleep (REM), as well as an increase in the time of stages 1 and 2 in patients with OSA. Sleep fragmentation in OSA patients confirmed an increase in the respiratory arousal index (Table 1).
We obtained results demonstrating changes in serum serotonin levels in patients with OSA before and after PAP. During the 12-week period, all patients used PAP 75-95\% of nights, with an average usage of $4-8 \mathrm{~h}$ per night, indicating excellent adherence, and demonstrated a significant reduction in AHI (19.8-7.2 events/ $\mathrm{h}-$ residual $\mathrm{AHI}$ ) and normalization of the apnea index (AI) (17.4-2.4 events/h), indicating adequate treatment.

\section{DISCUSSION}

Before PAP treatment, the serotonin levels were lower compared to the post-treatment values. It is known that the serotonin system is a potent modulator of the neuronal pathways that control respiration [28-30]. Thus, our results are consistent with other studies showing changes in the regulation of the serotonin system at the level of neuronal interactions that may contribute to the onset of OSA [31]. At the same time, the genetic predisposition of the

Table 1 Sleep data and serum serotonin levels in OSAS patients before and after CPAP therapy (Me [25; 75])

\begin{tabular}{lccc}
\hline & $\begin{array}{l}\text { Subjects with OSAS } \\
(\boldsymbol{n}=\mathbf{3 0})\end{array}$ & $\begin{array}{l}\text { Subjects with OSAS after 3 months of CPAP } \\
(\boldsymbol{n}=\mathbf{3 0})\end{array}$ & $\begin{array}{l}\boldsymbol{p} \text {-value } \\
(\boldsymbol{\omega})\end{array}$ \\
\hline $\mathrm{AHI}($ events/h) & $19.8(16.7-38.0)$ & $7.2(4.2-10.4)$ & 0.001 \\
$\mathrm{AI}($ events/h) & $17.4(15.1-24.7)$ & $2.4(1.1-4.6)$ & 0.001 \\
$\begin{array}{l}\text { Respiratory arousal index } \\
\quad(\text { events/h) }\end{array}$ & $56.1(41.3-73.0)$ & $27.2(27.1-35.8)$ & 0.003 \\
Average $\mathrm{SpO}_{2}$ values (\%) & $86.7(82.4-90.2)$ & $91.5(90-95)$ & \\
$\mathrm{SpO}_{2}<90 \%$ (\% of total sleep & $45.7(42.4-56.8)$ & $6.2(5.2-12.3)$ & 0.003 \\
$\quad$ time) & $82.5(83.1-88.7)$ & $90.1(91.5-98.4)$ & 0.003 \\
Sleep efficiency (\%) & $256.3(232.0-276.2)$ & $180.3(170.0-226.2)$ & 0.001 \\
Stages 1-2 NREM (min) & $89.2(69.1-105.4)$ & $98.06(89.06-145.4)$ & 0.001 \\
Stage 3 NREM (min) & $87.0(62.0-95.0)$ & $105.8(102.6-140.1)$ & 0.001 \\
REM (min) & $20.3(15.1-26.2)$ & $26.03(19.1-30.8)$ & 0.001 \\
Serum serotonin $(\mathrm{ng} / \mathrm{mL})$ & & 0.036 \\
\hline
\end{tabular}

$\omega$, Wilcoxon $t$-test;

OSAS obstructive sleep apnea syndrome, $C P A P$ continuous positive airway pressure, $N R E M$ non-rapid eye movement sleep, $R E M$ rapid eye movement sleep, $A H I$ apnea hypopnea index, $A I$ apnea index, $S p O_{2}$ oxygen saturation 
serotonergic system formation is being actively discussed. The serotonin transporter gene polymorphism (SLC6A4) leads to changes in serotonin levels, which suggests that it is an important link in the pathogenesis of OSA [32, 33]. A meta-analysis by Maierean et al. [34] of studies investigating serotonin polymorphisms showed the course of OSA and dependence on serotonin genetic modification.

Thus, the prevalence of the L/L genotype in men is higher, which explains the male predisposition to OSA. In addition, the long (L) allele was associated with a higher AHI and longer sleep time in oxygen desaturation levels below $90 \%$. In contrast, the presence of the short (S) allele may play a protective role in the development of OSA while also influencing sleep quality, contributing to insomnia and depression [35].

At the same time, the elimination of intermittent hypoxia during sleep in patients with OSA leads to an increase in blood serotonin levels similar to those in healthy individuals. It is well known that the elimination of hypoxia leads to an improvement in the sleep structure [18, 36-39]. However, the results of previous experimental studies demonstrated that serotonin systems, serotonin, and its metabolites affected the regulation of the sleep-wake cycle [40-44]. Our results confirm the hypothesis about a change in serum serotonin levels upon elimination of intermittent hypoxia during the night in patients with OSA. Tripathi et al. [45] also confirmed this hypothesis by finding an inverse correlation between the severity of OSA and the concentration of serum serotonin in elderly patients with orthodontic pathology and obesity [45].

The revelation of the role of serotonin in the development of OSA opens up many diagnostic and therapeutic possibilities. Thus, a therapeutic "window" of opportunity for serotonin was proposed by Veasey et al. [46, 47]. Experimental work was carried out with the introduction of a serotonin antagonist on English bulldogs with OSA. Suppression of endogenous serotonin levels caused airway obstruction in animals while awake. Likewise, the possibility of using serotonin as an OSA biomarker was considered by Lipford et al. [48]. This may open up new perspectives in the study of serotonin in breathing disorders during sleep. This is a preliminary study, so it has a number of limiting aspects, primarily the small sample size. It is also necessary to study polymorphisms of the serotonin modulator gene and associations between serotonin and body weight, gender, and ethnicity. We understand that longer PAP therapy is needed ( 12 months and more) in order to eliminate residual AHI.

\section{CONCLUSION}

Our preliminary results suggest that the elimination of intermittent hypoxia increases serotonin levels. This could be interpreted as a criterion for the effectiveness of PAP therapy and an improvement in sleep quality.

\section{ACKNOWLEDGEMENTS}

This work was performed with the use of equipment of Collective research centre "Center for the development of progressive personalized technologies for health" SC FHHRP, Irkutsk. We would like to thank all the staff of the Laboratory of pathophysiology, the Laboratory of personalized of medicine, the Centre of innovation of medicine of the Scientific Centre for Family Health and Human Reproduction Problems. We also would like to thank the patients who agreed to participate in this study.

Funding. No funding or sponsorship was received for this study or publication of this article. The Rapid Service Fee was funded by the authors.

Authorship. All named authors meet the International Committee of Medical Journal Editors (ICMJE) criteria for authorship for this article, take responsibility for the integrity of the work as a whole, and have given their approval for this version to be published.

Authors' Contribution. Conceptualization: Irina M. Madaeva, Olga N. Berdina, Natalya V. Semenova; Methodology: Irina M. Madaeva, 
Nadezhda A. Kurashova, Aleksey V. Belskikh; Formal analysis: Irina M. Madaeva, Olga N. Berdina; Investigation: Irina M. Madaeva, Olga N. Berdina, Nadezhda A. Kurashova, Erdem B. Ukhinov, Natalya V. Semenova; Writing original draft preparation and final manuscript preparation: Irina M. Madaeva, Olga N. Berdina; Natalya V. Semenova; Statistical analysis: Nadezhda A. Kurashova, Olga N. Berdina; Validation: Lyubov I. Kolesnikova. All authors have read and agreed to the published version of the manuscript.

Disclosures. Irina M. Madaeva has nothing to disclose. Olga N. Berdina has nothing to disclose. Nadezhda A. Kurashova has nothing to disclose. Natalya V. Semenova has nothing to disclose. Erdem B. Ukhinov has nothing to disclose. Aleksey V.Belskikh has nothing to disclose. Lyubov I. Kolesnikova has nothing to disclose.

Compliance with Ethical Standards. All procedures performed in this study involving human participants were in accordance with the ethical standards of the national research committee and with the 1964 Helsinki declaration and its later amendments. This study has been approved by the Scientific Centre for Family Health and Human Reproduction Problems Committee on Biomedical Ethics. (20.02.2019, protocol N2). Informed consent was obtained from all individual participants included in the study.

Data Availability. The datasets generated during and/or analyzed during the current study are available from the corresponding author on reasonable request.

Open Access. This article is licensed under a Creative Commons Attribution-NonCommercial 4.0 International License, which permits any non-commercial use, sharing, adaptation, distribution and reproduction in any medium or format, as long as you give appropriate credit to the original author(s) and the source, provide a link to the Creative Commons licence, and indicate if changes were made. The images or other third party material in this article are included in the article's Creative Commons licence, unless indicated otherwise in a credit line to the material. If material is not included in the article's Creative Commons licence and your intended use is not permitted by statutory regulation or exceeds the permitted use, you will need to obtain permission directly from the copyright holder. To view a copy of this licence, visit http:// creativecommons.org/licenses/by-nc/4.0/.

\section{REFERENCES}

1. Berry RB, Budhiraja R, Gottlieb DJ, et al. Rules for scoring respiratory events in sleep: update of the 2007 AASM Manual for the Manual for the Scoring of Sleep and Associated Events. Deliberations of the Sleep Apnea Definitions Task Force of the American Academy of Sleep Medicine. J Clin Sleep Med. 2012;8(5):597-619. https://doi.org/10.5664/jcsm. 2172.

2. Peppard PE, Young T, Barnet JH, Palta M, Hagen EW, Hla KM. Increased prevalence of sleep-disordered breathing in adults. Am J Epidemiol. 2013;177(9):1006-14.

3. Lévy P, Kohler M, McNicholas WT, et al. Obstructive sleep apnoea syndrome. Nat Rev Dis Primers. 2015;1:15015.

4. Garvey JF, Pengo MF, Drakatos P, Kent BD. Epidemiological aspects of obstructive sleep apnea. J Thorac Dis. 2015;7(5):920-9. https://doi.org/10. 3978/j.issn.2072-1439.2015.04.52.

5. Parati G, Lombardi C, Castagna F, Mattaliano P, Filardi PP, Agostoni P. Heart failure and sleep disorders. Nat Rev Cardiol. 2016;13(7):389-403. https://doi.org/10.1038/nrcardio.2016.71.

6. Wu Z, Chen F, Yu F, Wang Y, Guo Z. A meta-analysis of obstructive sleep apnea in patients with cerebrovascular disease. Sleep Breath. 2017. https:// doi.org/10.1007/s11325-017-1604-4.

7. Benjafield AV, Ayas NT, Eastwood PR, et al. Estimation of the global prevalence and burden of obstructive sleep apnoea: a literature-based analysis. Lancet Respir Med. 2019;7:687.

8. Dempsey JA, Veasey SC, Morgan BJ, O’Donnell CP. Pathophysiology of sleep apnea. Physiol Rev. 2010;90(1):47-112. physrev.00043.2008. 
9. Magda Fattah RA, Jung SW, Greenspan MA, Padilla M, Enciso R. Efficacy of antidepressants in the treatment of obstructive sleep apnea compared to placebo. A systematic review with meta-analyses. Sleep Breath. 2020;24:443-53. https://doi.org/10. 1007/s11325-019-01954-9.

10. Kaur S, De Luca R, Khanday MA, Bandaru SS, Thomas RC, Broadhurst RY, Saper CB. Role of serotonergic dorsal raphe neurons in hypercapnia-induced arousals. Nat Commun. 2020. https://doi.org/10. 1038/s41467-020-16518-9.

11. Saboisky JP, Stashuk DW, Hamilton-Wright A, Carusona AL, Campana LM, Trinder J, Eckert DJ, Jordan AS, McSharry DG, White DP, Nandedkar S. Neurogenic changes in the upper airway of patients with obstructive sleep apnea. Am J Respir Crit Care Med. 2012;185:322-9. https://doi.org/10.1164/ rccm.201106-1058OC.

12. Smith I, Lasserson TJ, Wright J. Drug therapy for obstructive sleep apnoea in adults. Cochrane Database of Syst Rev. 2006;2:CD003002.

13. Veasey SC. Serotonin agonists and antagonists in obstructive sleep apnea: terapeutic potential. Am J Respir Med. 2003;2(1):21-9.

14. Cheng JY. Serotonin reuptake inhibitors in obstructive sleep apnea: associations in people with and without epilepsy. Neurol Res Int. 2018. https:// doi.org/10.1155/2018/7247605.

15. Sullivan CE, Issa FG, Berthon-Jones $\mathrm{M}$, Eves L. Reversal of obstructive sleep apnoea by continuous positive airway pressure applied through the nares. Lancet. 1981;1(8225):862-5.

16. Kushida CA, Chediak A, Berry RB, et al. Clinical guidelines for the manual titration of positive airway pressure in patients with obstructive sleep apnea. J Clin Sleep Med. 2008;4(2):157-71.

17. Patil SP, Ayappa IA, Caples SM, Kimoff RJ, Patel SR, Harrod CG. Treatment of adult obstructive sleep apnea with positive airway pressure: an American Academy of Sleep Medicine clinical practice guideline. J Clin Sleep Med. 2019;15(2):335-43.

18. Panoutsopoulos A, Kallianos A, Kostopoulos K, Seretis C, Koufogiorga E, Protogerou A, Trakada G, Kostopoulos C, Zakopoulos N, Nikolopoulos I. Effect of CPAP treatment on endothelial function and plasma CRP levels in patients with sleep apnea. Med Sci Monit. 2012;18(12):CR747-51. https://doi. org/10.12659/msm.883603.

19. Félez M, Grau N, Ruiz A, Guardiola E, Sanjuas C, Estirado C, Navarro-Muñoz M, Pascual A, OrozcoLevi M, Gea J. Increased urinary erythropoietin excretion in severe sleep apnea-hipoapnea syndrome: the effect of CPAP. Arch Bronconeumol. 2018;54(5):255-9. https://doi.org/10.1016/j.arbres. 2017.10.013.

20. Hecht L, Möhler R, Meyer G. Effects of CPAP-respiration on markers of glucose metabolism in patients with obstructive sleep apnoea syndrome: a systematic review and meta-analysis. Ger Med Sci. 2011. https://doi.org/10.3205/000143.

21. Chung F, Abdullah HR, Liao P. STOP-bang questionnaire. Chest. 2016;149(3):631-8. https://doi. org/10.1378/chest.15-0903.

22. American Academy of Sleep Medicine. International Classification of Sleep Disorders, 3rd edn.: Diagnostic and coding manual. American Academy of Sleep Medicine, Darien. 2014. https://rd. springer.com/chapter/. Doi: https://doi.org/10. 1007/978-1-4939-6578-6_27

23. Kapur VK, Auckley DH, Chowdhuri S, Kuhlmann DC, Mehra R, Ramar K, Harrod CG. Clinical practice guideline for diagnostic testing for adult obstructive sleep apnea: an American Academy of Sleep Medicine clinical practice guideline. J Clin Sleep Med. 2017;13(3):479-504. https://doi.org/10.5664/jcsm. 6506.

24. Epstein LJ, Kristo D, Strollo PJ Jr, Friedman N, Malhotra A, Patil SP, Ramar K, Rogers R, Schwab RJ, Weaver EM, Weinstein MD. Adult obstructive sleep apnea task force of the American academy of sleep medicine. Clinical guideline for the evaluation, management and long-term care of obstructive sleep apnea in adults. J Clin Sleep Med. 2009;5: 263-76.

25. Faccenda JF, Mackay TW, Boon NA, Douglas NJ. Randomized placebo-controlled trial of continuous positive airway pressure on blood pressure in the sleep apnea-hypopnea syndrome. Am J Respir Crit Care Med. 2001;163:344-8. https://doi.org/10. 1164/ajrccm.163.2.200503726.

26. Borsini EE, Blanco M, Ernst G, Salvado A, Bledel I, Nigro CA. Contribution of pulse oximetry in relation to respiratory flow events in a home-based approach aimed at diagnosing obstructive sleep apnea. Sleep Sci. 2021;14(1):77-81. https://doi.org/ 10.5935/1984-0063.20200042.

27. Nogueira F, Nigro C, Cambursano H, Borsini E, Silio J, Avila J. Practical guidelines for the diagnosis and treatment of obstructive sleep apnea syndrome. Medicina (B Aires). 2013;73(4):349-62.

28. Popa D, Léna C, Fabre V, Prenat C, Gingrich J, Escourrou P, Hamon M, Adrien J. Contribution of 5-HT2 receptor subtypes to sleep-wakefulness and respiratory control, and functional adaptations in 
knock-out mice lacking 5-HT2A receptors. J Neurosci. 2005;25(49):11231-8.

29. Alenina N, Bashammakh S, Bader M. Specification and differentiation of serotonergic neurons. Stem Cell Rev. 2006;2:5-10.

30. Richerson GB. Serotonergic neurons as carbon dioxide sensors that maintain $\mathrm{pH}$ homeostasis. Nat Rev Neurosci. 2004;5:449-61.

31. Yue W, Liu P, Hao W, et al. Association study of sleep apnea syndrome and polymorphisms in the serotonin transporter gene. Chin J Med Genet. 2005;22(5):533-6.

32. Yue W, Liu H, Zhang J, et al. Association study of serotonin transporter gene polymorphisms with obstructive sleep apnea syndrome in Chinese Han population. Sleep. 2008;31(11):1535-41. https:// doi.org/10.1093/sleep/31.11.1535.

33. Casale M, Pappacena M, Rinaldi V, Bressi F, Baptista $\mathrm{P}$, Salvinelli F. Obstructive sleep apnea syndrome: from phenotype to genetic basis. Curr Genomics. 2009;10(2):119-26. https://doi.org/10.2174/ 138920209787846998.

34. Maierean AD, Bordea IR, Salagean T, Hanna R, Alexescu TG, Chis A, Todea DA. Polymorphism of the serotonin transporter gene and the peripheral 5-hydroxytryptamine in obstructive sleep apnea: what do we know and what are we looking for? A systematic review of the literature. Nat Sci Sleep. 2021;13:125-39. S278170.

35. Prasad B, Carley DW, Herdegen JJ. Continuous positive airway pressure device-based automated detection of obstructive sleep apnea compared to standard laboratory polysomnography. Sleep Breath. 2010;14(2):101-7. https://doi.org/10.1007/ s11325-009-0285-z.

36. Pan H, Ren R, Li Y, Yang L, Huang G, Lei F, Du L, Tang X. Effects of continuous positive airway pressure on daytime sleepiness in patients with severe obstructive sleep apnea syndrome. Zhonghua Yi Xue Za Zhi. 2014;94(6):412-5.

37. Lee SA, Lee GH, Chung YS, Kim WS. Clinical, polysomnographic, and CPAP titration features of obstructive sleep apnea: mixed versus purely obstructive type. J Neurol Sci. 2015;355(1-2):150-4. https://doi.org/10.1016/j.jns.2015.06.005.
38. Yetkin O, Aydogan D. Effect of CPAP on sleep spindles in patients with OSA. Respir Physiol Neurobiol. 2018;247:71-3. https://doi.org/10.1016/j. resp.2017.09.008.

39. Murillo-Rodríguez E, Arias-Carrión O, SanguinoRodríguez K, González-Arias M, Haro R. Mechanisms of sleep-wake cycle modulation. CNS Neurol Disord Drug Targets. 2009;8(4):245-53. https://doi. org/10.2174/187152709788921654.

40. Hilaire G, Voituron N, Menuet C, Ichiyama RM, Subramanian HH, Dutschmann M. The role of serotonin in respiratory function and dysfunction. Respir Physiol Neurobiol. 2010;174:76-88.

41. Luppi PH. Neurochemical aspects of sleep regulation with specific focus on slow-wave sleep. World J Biol Psychiatry. 2010;1:4-8. https://doi.org/10. 3109/15622971003637611.

42. Espana RA, Scammell TE. Sleep neurobiology from a clinical perspective. Sleep. 2011;34:845-58.

43. Monti JM. Serotonin control of sleep-wake behavior. Sleep Med Rev. 2011;15:269-81.

44. Luppi P-H, Fort P. Sleep-wake physiology. Review. Handb Clin Neurol. 2019;160:359-70. https://doi. org/10.1016/B978-0-444-64032-1.00023-0.

45. Tripathi A, Bagchi S, Singh J, Tripathi S, Gupta NK, Arora V. Incidence of obstructive sleep apnea in elderly edentulous patients and the possible correlation of serum serotonin and apnea-hypopnea index. J Prosthodont. 2017. https://doi.org/10. 1111/jopr.12654.

46. Veasey SC, Panckeri KA, Hoffman EA, et al. The effects of serotonin antagonists in an animal model of sleep-disordered breathing. Am J Respir Crit Care Med. 1996;153:776-8.

47. Veasey SC. Serotonin agonists and antagonists in obstructive sleep apnea: therapeutic potential. Am J Respir Med. 2003;2(1):21-9. https://doi.org/10. 1007/BF03256636.

48. Lipford MC, Ramar K, Liang Y-J, Lin C-W, Chao Y-T, An J, Chiu C-H, Tsai Y-J, Shu C-H, Lee F-P, Chiang RP-Y. Biomarkers in obstructive sleep apnea. Sleep Med Rev. 2015. https://doi.org/10. 1016/j.smrv.2015.08.003. 